\title{
Characterization of a late blight resistance gene homologous to $R 2$ in potato variety Payette Russet
}

Hari S. Karki ${ }^{1}$, Dennis A. Halterman ${ }^{1}$, and Jeffrey B. Endelman ${ }^{2}$

${ }^{1}$ U.S. Department of Agriculture-Agricultural Research Service, Madison, WI 53706

${ }^{2}$ Department of Horticulture, University of Wisconsin-Madison, Madison, WI 53706

Corresponding author:

Jeffrey Endelman

1575 Linden Dr.

Madison, WI 53706

endelman@wisc.edu

Ph: 1-608-250-0754

Fax:1-608-262-4743

Running head: $R 2$ homolog in Payette Russet 


\begin{abstract}
Breeding for late blight resistance has traditionally relied on phenotypic selection, but as the number of characterized resistance $(\mathrm{R})$ genes has grown, so have the possibilities for genotypic selection. One challenge for breeding russet varieties is the lack of information about the genetic basis of resistance in this germplasm group. Based on observations of strong resistance by 'Payette Russet' to genotype US-23 of the late blight pathogen Phytophthora infestans in inoculated experiments, we deduced the variety must contain at least one major $\mathrm{R}$ gene. To identify the gene(s), $79 \mathrm{~F} 1$ progeny were screened using a detached leaf assay and classified as resistant vs. susceptible. Linkage mapping using markers from the potato SNP array revealed a single resistant haplotype on the short arm of chromosome group 4, which coincides with the R2/Rpi-abpt/Rpi-blb3 locus. PCR amplification and sequencing of the gene in Payette revealed it is homologous to $R 2$, and transient expression experiments in Nicotiana benthamiana confirmed its recognition of the Avr2 effector. Sequencing of a small diversity panel revealed a SNP unique to resistant haplotypes at the $R 2$ locus, which was converted to a KASP marker that showed perfect prediction accuracy in the F1 population and diversity panel. Although many genotypes of $P$. infestans are virulent against $R 2$, even when defeated this gene may be valuable as one component of a multi-genic approach to quantitative resistance.
\end{abstract}




\section{INTRODUCTION}

One of the most significant pathogens of potato (S. tuberosum L.) is the oomycete Phytophthora infestans, which causes late blight. In the USA and EU, growers typically apply fungicides for late blight control upwards of 10 times per season, at a cost of US\$500 per hectare (Johnson et al. 2000; Guenthner et al. 2001; Haverkort et al. 2008). Late blight also affects tubers and can render the harvested crop unmarketable from the field or following storage when susceptible varieties are left unprotected. To mitigate the economic impact of late blight, breeders have spent decades introgressing disease resistance into cultivated potato from wild relatives. Because of the autotetraploid $(2 n=4 x=48)$ genome of cultivated potato, however, this resistance is generally not fixed and must be selected in each generation. The selection process is more efficient, especially considering that many thousands of new clones are created by a single breeding program each year, when using genetic markers instead of via inoculated disease assays. Genetic markers are also critical when stacking multiple resistance genes (targeting different effectors in the pathogen) in a single variety.

A number of North American varieties have been developed with some degree of late blight resistance, but it is only recently that significant progress has been made toward identifying the genetic basis. One breakthrough was the potato SNP array (Hamilton et al. 2011; Felcher et al. 2012) combined with new software for genetic mapping (Hackett et al. 2014), which Massa et al. (2015) used to map the R gene in 'Jacqueline Lee' to the long arm of chromosome 9. This coincided with the published location of $R 8$ (Jo et al. 2011), leading to the hypothesis that $R 8$ was responsible for the resistance, which was confirmed by Vossen et al. (2016). Another breakthrough was the development of DNA bait libraries based on all predicted NB-LRR genes in the potato genome (Jupe et al. 2013). This method, called RenSeq, relies on hybridization of genomic DNA with the bait library to isolate candidate genes for more economical sequencing. Although originally used for mapping unknown $\mathrm{R}$ genes, it can also be used to detect previously characterized $\mathrm{R}$ genes (Armstrong et al. 2019).

The first aim of the current project was to identify the genetic basis of resistance in 'Payette Russet', which was released as a fry processing variety in 2015 and publicized as late blightresistant based on inoculated field trials in Oregon and Idaho (Novy et al. 2017). Our interest was piqued after observing almost no injury to Payette in a whole-plant assay with $P$. infestans genotype US-23, while the other potato genotypes in the experiment were largely destroyed. In addition to isolating and characterizing the $\mathrm{R}$ gene in Payette, we developed a KASP marker that can be used for breeding.

\section{MATERIALS AND METHODS Plant material and late blight assay}

The F1 population W16215 was generated by crossing Payette Russet with A0012-5 (GemStar Russet $\times$ Wallowa Russet). A Wisconsin isolate of $P$. infestans genotype US-23 was used to screen both parents and the $\mathrm{F} 1$ population (grown from seed tubers in a greenhouse). The isolate was maintained on Rye A media at $18^{\circ} \mathrm{C}$ and refreshed periodically. Sporangia were harvested from 12-14 day-old culture plates by flooding with ice cold water and then kept at $4^{\circ} \mathrm{C}$ for 2-4 hours to release zoospores. The detached leaf assay protocol of Vleeshouwers et al. (1999) was followed with some modifications. Briefly, compound leaves having at least three leaflets were collected from 5-8 week-old plants into Nunc assay plates with a moist paper towel. The abaxial side of each leaflet was inoculated (4 to 6 droplets per leaflet) with $10-\mu l$ 
droplets of zoospores (50,000 zoospores per $\mathrm{ml})$, and samples were stored in an incubator at $16^{\circ} \mathrm{C}$ and $16 \mathrm{~h}$ daylight. Disease was scored 7 days after inoculation using a 1-9 scale (Karki et al. 2020), and offspring were ultimately classified as resistant (scores 7-9) vs. susceptible (scores 1-4) after three replications.

\section{SNP array genotyping and genetic mapping}

Both parents and the F1 population were genotyped at the University of Minnesota using version 3 of the potato SNP array. Genomic DNA was extracted with the DNeasy Plant Maxi Kit (QIAGEN, Hilden, Germany) according to the manufacturer instructions. Genotype calls were made using the fitPoly R package (Voorrips et al. 2011; Zych et al. 2019). R package MAPpoly (Mollinari et al. 2020) was used to phase the parental genotypes and calculate identity-bydescent (IBD) probabilities for each offspring based on the SNP positions in version 4.03 of the DM reference genome (Potato Genome Sequencing Consortium 2011; Sharma et al. 2013). R packages diaQTL (available at https://github.com/jendelman/diaQTL) and BGLR (Pérez and de los Campos 2014) were used to map the binary resistance phenotype (R/S) via Bayesian probit regression on the IBD probabilities. The LOD score for each marker was calculated as the difference in log-likelihood (evaluated at the posterior mean) between the QTL and no-QTL model. The predictive ability of each marker was quantified based on the phi-correlation coefficient for the $2 \times 2$ contingency table between the predicted and observed responses.

\section{$R$ gene isolation and validation in $N$. benthamiana}

The primers used to isolate Rpi-blb3 (Lokossou et al. 2009) were modified (Table S1) to amplify the $\mathrm{R}$ gene in Payette by including additional 5' and $3^{\prime}$ overhangs to facilitate cloning into custom USER expression vectors (kindly provided by The Sainsbury Laboratory, Norwich, UK). The gene was amplified by PCR in a $25 \mu \mathrm{l}$ reaction with initial denaturation of $95^{\circ} \mathrm{C}$ for 3 min, 30 cycles of $\left[98^{\circ} \mathrm{C}\right.$ for $20 \mathrm{sec}, 65^{\circ} \mathrm{C}$ for $30 \mathrm{sec}$, and $72^{\circ} \mathrm{C}$ for $3 \mathrm{~min}$ ], and final extension of $72^{\circ} \mathrm{C}$ for $10 \mathrm{~min}$ using KAPA master mix (Roche). PCR products were visualized using a $0.8 \%$ agarose gel, then excised and purified using the Zymoclean DNA recovery kit (Zymo Research) according to the manufacturer's instructions. The purified DNA fragment (40 ng) was ligated into pICSLUS0003OD (35S USER vector) with the USER enzyme (New England Biolabs). After verifying the presence of the insert by colony PCR, purified plasmids from two clones were submitted for next-generation sequencing and contig assembly (using SPAdes) at the Purdue Genomics Core Facility (Purdue University, West Lafayette, IN). Contigs were mapped against the reference sequence Rpi-abpt (GenBank Accession No. FJ536324.1) using Geneious Prime® 2019.0.4.

To verify the functionality of the $\mathrm{R}$ gene isolated from Payette Russet, purified plasmid was used for transformation of A.tumefaciens strain GV3101. In the first experiment, overnight culture of Agrobacterium was centrifuged, washed, and suspended in MMA media (Abdullah and Halterman 2018) to $\mathrm{OD}_{600}=0.2$, followed by infiltration of $N$. benthamiana leaves (collected after 4-5 weeks of growth at $26^{\circ} \mathrm{C}$ and $12 \mathrm{~h}$ daylight) with a needleless $1 \mathrm{~mL}$ syringe. Agrobacterium culture containing Rpi-abpt (kindly provided by Jack Vossen, Wageningen University \& Research) was used as a positive control. $24 \mathrm{~h}$ after infiltration, a detached leaf assay using $P$. infestans genotype US-23 was performed as described above. For the second experiment, equal volumes of Agrobacterium culture containing the R gene and effector Avr2 (Gilroy et al. 2011; kindly provided by Jack Vossen, Wageningen University \& Research) were mixed after centrifugation, washing, and suspension in MMA media to $\mathrm{OD}_{600}=0.4$. 
$N$. benthamiana leaves were infiltrated with the mixed culture and evaluated after 6 days. The cell death-inducing elicitin INF1 was used as a positive control (Kamoun et al. 1998).

\section{KASP marker design}

To identify a SNP unique to resistant haplotypes at the R2/Rpi-abpt/Rpi-blb3 locus, the primers (Table S1) and PCR amplification protocol described above were applied to a larger set of varieties. PCR products (Fig. S1) were purified using the Zymoclean DNA recovery kit (Zymo Research) and submitted (without cloning into plasmids) for next-generation sequencing and contig assembly at the Purdue Genomics Core Facility (Purdue University, West Lafayette, IN). Contigs were mapped against the Rpi-abpt ${ }^{\mathrm{T} 87}$ haplotype from Payette Russet and aligned using Geneious Prime® 2019.0.4. 50 bp of flanking sequence on either side of the target SNP was submitted to LGC Genomics (MA, USA) for KASP marker design and validation.

\section{RESULTS}

\section{Payette contains a homolog of $\boldsymbol{R} 2$}

An F1 population containing 79 progeny of Payette Russet was screened for resistance to the US-23 genotype of $P$. infestans via detached leaf assay. Clear visual differences (Fig. 1) were observed for resistant (R) vs. susceptible (S) phenotypes to allow for binary classification. The ratio 36R:43S was not significantly different than $1: 1\left(\chi^{2}=0.62, p=0.4\right)$, suggesting one $\mathrm{R}$ gene with simplex dosage. The population was genotyped with version 3 of the potato SNP array, which generated 11,094 polymorphic markers. Genetic mapping confirmed the presence of a single resistant haplotype on the short arm of chromosome group 4 (Fig. 2).

Based on this location, we hypothesized the $\mathrm{R}$ gene to be homologous to R2, Rpi-abpt, and Rpi-blb3 (Li et al. 1998; Park et al. 2005a; Park et al. 2005b; Lokossou et al. 2009). The primers for Rpi-blb3 generated an amplicon of the expected size $(\sim 2.5 \mathrm{~kb})$, which was cloned into a plasmid for sequencing. Two clones were sequenced, and both were identical to the published sequence for Rpi-abpt except for a synonymous $\mathrm{C} \rightarrow \mathrm{T}$ substitution at position 87 (relative to the start of the coding sequence). This matches the haplotype in Pentland Dell discovered by Armstrong et al. (2019), who reported the $C \rightarrow T$ substitution at position 86 instead of 87 based on the bp numbering convention of the BED file format (I. Hein, personal communication).

$N$. benthamiana was used to verify the functionality of the $R 2$ homolog isolated from Payette. Leaves infiltrated with Agrobacterium harboring the gene showed no signs of late blight when inoculated with $P$. infestans genotype US-23 (Fig. 3A \& B), and co-infiltration with Agrobacterium culture harboring Avr2 resulted in a hypersensitive response (Fig. 3C), thereby confirming recognition of this effector.

\section{Design and application of a KASP marker}

To identify a SNP unique to resistant haplotypes at the $R 2 / R p i$-abpt/Rpi-blb3 locus, the same primers used to isolate the $R p i$ - $a b p t^{\mathrm{T} 87}$ haplotype from Payette were applied to a diverse set of potato varieties (Saginaw Chipper, Jacqueline Lee, Palisade Russet, ND028673B-2Russ, A00125, Red Prairie, and Rio Colorado) that, based on their susceptible phenotype in the detached leaf assay, were presumed to lack a functional $R 2$ homolog. PCR products were purified and submitted for next-generation sequencing. The number of gene-length contigs that mapped to the Rpi-abpt ${ }^{\mathrm{T} 87}$ sequence ranged from 0 to 5 per variety (Fig. 4). From Payette Russet, which was used as a positive control in the experiment, a second haplotype was discovered with a $420 \mathrm{bp}$ insertion and premature stop codon. This second haplotype was not discovered during the initial 
sequencing, presumably because of the small number of clones that were sequenced. Based on visual inspection of the multiple sequence alignment, we noticed that the resistant haplotypes (first five in Fig. 4) all contained $\mathrm{C}$ at $2223 \mathrm{bp}$ (from the beginning of the coding sequence for Rpi-abpt), while the susceptible haplotypes contained T, making it an ideal SNP for breeding.

The C/T SNP and flanking sequence were submitted for KASP marker design (Table 1) and genotyping of the small diversity panel and F1 population used for mapping. Samples were also genotyped using the $R 2$ KASP marker published by Meade et al. (2020). Both KASP markers had a perfect correlation with the resistance phenotype in the F1 population and correctly predicted the absence of an $R 2$ homolog in the diversity panel.

\section{DISCUSSION}

Our results demonstrate that $R p i-a b p t^{\mathrm{T} 87}$ provides strong resistance to the US-23 genotype of $P$. infestans, which is currently the most common genotype in the USA, and this resistance is available in an elite russet background. How will this impact breeding? Although there is a long history of using $R 2$ homologs in Europe, it is no longer a primary target because many isolates of $P$. infestans are virulent against it. As mentioned already, the functional Payette haplotype is identical to that in Pentland Dell, which was released in Great Britain in 1963 and promoted as having durable resistance due to the presence of three $\mathrm{R}$ genes $(R 1, R 2, R 3)$. This contributed to its rapid adoption, becoming the third most popular variety by 1968 , but widespread late blight on Pentland Dell that year shattered the illusion of durable resistance (Malcolmson 1969). Pilet et al. (2005) reported that, prior to the large scale deployment of cultivars containing $R 2$ homologs in western France, the onset of late blight on those cultivars was significantly later compared to susceptible varieties, and most $P$. infestans isolates were avirulent. However, these advantages sharply decreased as the acreage of $R 2$-containing varieties increased. Even within the USA, the avirulence of US-23 against Rpi-abpt ${ }^{\mathrm{T} 87}$ may be somewhat anomalous, as most of the formerly dominant $P$. infestans genotypes, such as US-8, were reported to be virulent against $R 2$ (Goodwin et al. 1995). Due to the scarcity of sexually compatible mating types in the US, however, $P$. infestans populations tend to evolve more slowly and may have difficulty overcoming $R p i$-abpt ${ }^{\mathrm{T} 87}$ if it becomes more widely deployed.

One response to the perennial tug-of-war between $P$. infestans adaptation and resistance breeding has been to avoid major $\mathrm{R}$ genes and select for quantitative late blight resistance in the field (Wastie 1991). This is challenging in the context of current best practice for breeding, which emphasizes rapid parent selection driven by genomic prediction (Slater et al. 2014; Cobb et al. 2019), because hundreds of clones would need to be evaluated each year to maintain accuracy of the prediction model. Such trials are prohibited in some states (such as Wisconsin), and even when they are allowed, require significant resources. Our view is that stacking R genes is still valuable, and readily accomplished with genomic selection, since even defeated $\mathrm{R}$ genes can contribute to quantitative resistance (Stewart et al. 2003; St. Clair 2010). For many programs, the goal of breeding for late blight resistance is to delay when preventive fungicide applications begin or reduce their frequency, not completely eliminate them. Viewed in this conext, our discovery of an $R 2$ homolog in Payette can benefit russet variety development.

\section{Acknowledgments}

Funding for this research was provided by the Wisconsin Potato and Vegetable Growers Association, the USDA NIFA/NSF Plant Biotic Interactions Program Award 2018-67014-28488, 
and PepsiCo. We thank Grace Christensen and Peyton Sorensen for their assistance in the lab and greenhouse, as well as personnel at the UW Rhinelander Agricultural Research Station.

\section{References}

Abdullah, S., and D. Halterman. 2018. Methods for transient gene expression in wild relatives of potato. In Plant Pathogenic Fungi and Oomycetes: Methods and Protocols, eds. W. Ma and T. Wolpert, 131-138. New York: Humana Press. https://doi.org/10.1007/978-1-4939-87245_11.

Armstrong, M.R., J. Vossen, T.Y. Lim, R.C.B. Hutten, J. Xu, S.M. Strachan, B. Harrower, N. Champouret, E.M. Gilroy, and I. Hein. 2019. Tracking disease resistance deployment in potato breeding by enrichment sequencing. Plant Biotechnology Journal 17: 540-549. https://doi.org/10.1111/pbi.12997.

Cobb, J.N., R.U. Juma, P.S. Biswas, J.D. Arbalaez, J. Rutkoski, G. Atlin, T. Hagen, M. Quinn, and E.H. Ng. 2019. Enhancing the rate of genetic gain in public-sector plant breeding programs: lessons from the breeder's equation. Theoretical and Applied Genetics. 132: 627645.

Felcher, K.J., J.J. Coombs, A.N. Massa, C.N. Hansey, J.P. Hamilton, R.E. Veilleux, C.R. Buell, and D.S. Douches. 2012. Integration of two diploid potato linkage maps with the potato genome sequence. PLoS ONE 7:e36347.

Gilroy, E.M., S. Breen, S.C. Whisson, J. Squires, I. Hein, M. Kaczmarek, D. Turnbull, P.C. Boevink, A. Lokossou, L.M. Cano, J. Morales, A.O. Avrova, L. Pritchard, E. Randall, A. Lees, F. Govers, P. van West, S. Kamoun, V.G.A.A. Vleeshouwers, D.E.L. Cooke and P.R.J. Birch. 2011. Presence/absence, differential expression and sequence polymorphisms between PiAVR2 and PiAVR2-like in Phytophthora infestans determine virulence on R2 Plants. New Phytologist 191: 763-776. https://doi.org/10.1111/j.1469-8137.2011.03736.x.

Goodwin, S.B., L.S. Sujkowski, and W.E. Fry. 1995. Rapid evolution of pathogenicity within clonal lineages of the potato late blight disease fungus." Phytopathology 85: 669-676. https://doi.org/10.1094/Phyto-85-669.

Guenthner, J.F., K.C. Michael, and P. Nolte. 2001. The economic impact of potato late blight on US growers. Potato Research 44: 121-125. http://doi.org/10.1007/BF02410098

Hackett, C.A., J.E. Bradshaw, and G.J. Bryan. 2014. QTL mapping in autotetraploids using SNP dosage information. Theoretical and Applied Genetics 127: 1885-1904.

Hamilton, J.P., C.N. Hansey, B.R. Whitty, K. Stoffel, A.N. Massa, A. Van Deynze, W.S. De Jong, D.S. Douches, and C.R. Buell. 2011. Single nucleotide polymorphism discovery in elite North American potato germplasm. BMC Genomics 12:302.

Haverkort, A.J., P.M.Boonekamp, R. Hutten, E. Jacobsen, L.A.P Lotz, G.J.T. Kessel, R.G.F. Visser, and E.A.G. van der Vossen. 2008. Societal costs of late blight in potato and prospects of durable resistance through cisgenic modification. Potato Research 51: 47-57.

Jo, K.R., M. Arens, T.Y. Kim, J.A. Jongsma, R.G.F. Visser, E. Jacobsen, and J.H. Vossen. 2011. Mapping of the $S$. demissum late blight resistance gene $R 8$ to a new locus on chromosome IX. Theoretical and Applied Genetics. 123: 1331-1340.

Johnson, D.A., T.F. Cummings, and P.B. Hamm. 2000. Cost of fungicides used to manage potato late blight in the Columbia Basin: 1996 to 1998. Plant Disease 84:399-402.

Jupe, F., K. Witek, W. Verweij, J. Śliwka, L. Pritchard, G.J. Etherington, D. Maclean, P.J. Cock, R.M. Leggett, G.J. Bryan, L. Cardle, I. Hein, and J.D.G. Jones. 2013. Resistance gene enrichment sequencing (RenSeq) enables reannotation of the NB-LRR gene family from 
sequenced plant genomes and rapid mapping of resistance loci in segregating populations.

Plant Journal 76: 530-544. https://doi.org/10.1111/tpj.12307.

Kamoun, S., P. van West, V.G.A.A. Vleeshouwers, K.E. De Groot, and F. Govers. 1998.

Resistance of Nicotiana benthamiana to Phytophthora infestans is mediated by the recognition of the elicitor protein INF1." Plant Cell 10: 1413-1425.

https://doi.org/10.1105/tpc.10.9.1413.

Karki, H., S. Jansky, and D. Halterman. 2020. Screening of wild potatoes identifies new sources of late blight resistance. Plant Disease (published online 5 Aug. 2020). https://doi.org/10.1094/PDIS-06-20-1367-RE.

Li, X., H.J. van Eck, J.N.A.M. Rouppe van der Voort, D.-J. Huigen, P. Stam, and E. Jacobsen. 1998. Autotetraploids and genetic mapping using common AFLP markers: the R2 allele conferring resistance to Phytophthora infestans mapped on potato chromosome 4. Theoretical and Applied Genetics 96: 1121-1128. https://doi.org/10.1007/s001220050847.

Lokossou, A.A., T.-H. Park, G. van Arkel, M. Arens, C. Ruyter-Spira, J. Morales, S. C. Whisson, P.R.J. Birch, and R.G.F. Visser. 2009. Exploiting knowledge of R/Avr genes to rapidly clone a new LZ-NBS-LRR family of late blight resistance genes from potato linkage group IV. Molecular Plant-Microbe Interactions 22: 630-641. https://doi.org/10.1094/MPMI-22-6-0630.

Malcolmson, J.F. 1969. Races of Phytophthora infestans occurring in Great Britain. Transactions of the British Mycological Society 53: 417-423. https://doi.org/https://doi.org/10.1016/S0007-1536(69)80099-9.

Massa, A.N., N.C. Manrique-Carpintero, J.J. Coombs, D.G. Zarka, A.E. Boone, W.W. Kirk, C.A. Hackett, G.J. Bryan, and D.S. Douches. 2015. Genetic linkage mapping of economically important traits in cultivated tetraploid potato (Solanum tuberosum L.). G3: Genes, Genomes, Genetics 5: 2357-2364.

Meade, F., S. Byrne, D. Griffin, C. Kennedy, F. Mesiti, and D. Milbourne. 2020. Rapid development of KASP markers for disease resistance genes using pooled whole-genome resequencing. Potato Research 63: 57-73. https://doi.org/10.1007/s11540-019-09428-X.

Mollinari, M., B.A. Olukolu, G. da S. Pereira, A. Khan, D. Gemenet, G.C. Yencho, and Z.-B. Zeng. 2020. Unraveling the hexaploid sweetpotato inheritance using ultra-dense multilocus mapping. G3: Genes, Genomes, Genetics 10: 281-292. https://doi.org/10.1534/g3.119.400620.

Novy, R. G., J.L. Whitworth, J.C. Stark, B.L. Schneider, N.R. Knowles, M.J. Pavek, L.O. Knowles, B.A. Charlton, V. Sathuvalli, S. Yilma, C.R. Brown, M. Thornton, T.L. Brandt, and N. Olsen. 2017. Payette Russet: a dual-purpose potato cultivar with cold-sweetening resistance, low acrylamide formation, and resistance to late blight and potato virus $\mathrm{Y}$. American Journal of Potato Research 94: 38-53. https://doi.org/10.1007/s12230-016-95460 .

Park, T.-H., J. Gros, A. Sikkema, V.G.A.A. Vleeshouwers, M. Muskens, S. Allefs, E. Jacobsen, R.G.F. Visser, and E.A.G. van der Vossen. 2005a. The late blight resistance locus Rpi-blb3 from Solanum bulbocastanum belongs to a major late blight $\mathrm{R}$ gene cluster on chromosome 4 of potato. Molecular Plant-Microbe Interactions 18: 722-729. https://doi.org/10.1094/MPMI-18-0722.

Park, T.-H., V.G.A.A. Vleeshouwers, R.C.B. Hutten, H.J. van Eck, E. van der Vossen, E. Jacobsen, and R.G.F. Visser. 2005b. High-resolution mapping and analysis of the resistance locus Rpi-abpt against Phytophthora infestans in potato. Molecular Breeding 16: 33-43. 
https://doi.org/10.1007/s11032-005-1925-z.

Pérez, P., and G. de los Campos. 2014. Genome-wide regression and prediction with the BGLR statistical package. Genetics 198: 483-495. https://doi.org/10.1534/genetics.114.164442.

Pilet, F., R. Pellé, D. Ellissèche, and D. Andrivon. 2005. Efficacy of the $R 2$ resistance gene as a component for the durable management of potato late blight in France." Plant Pathology 54: 723-732. https://doi.org/10.1111/j.1365-3059.2005.01288.x.

Potato Genome Sequencing Consortium. 2011. Genome sequence and analysis of the tuber crop potato. Nature 475: 189-195. https://doi.org/10.1038/nature10158.

Sharma, S.K., D. Bolser, J . de Boer, M. Sønderkaer, W . Amoros, M.F. Carboni, J.M. D'Ambrosio, G. de la Cruz, A. Di Genova, D.S. Douches, M. Eguiluz, X. Guo, F . Guzman, C.A. Hackett, J.P. Hamilton, G. Li, Y. Li, R. Lozano, A. Maass, D. Marshall, D. Martinez, K. McLean, N. Mejía, L. Milne, S. Munive, I. Nagy, O. Ponce, M. Ramirez, R. Simon, S.J. Thomson, Y. Torres, R. Waugh, Z. Zhang, S. Huang, R.G.F. Visser, C.W.B, Bachem, B. Sagredo, S.E. Feingold, G. Orjeda, R.E .Veilleux, M. Bonierbale, J.M.E. Jacobs, D. Milbourne, D.M.A Martin, and G.J. Bryan. 2013. Construction of reference chromosomescale pseudomolecules for potato: Integrating the potato genome with genetic and physical maps. G3: Genes, Genomes, Genetics 3: 2031-2047.

Slater, A.T., N.O.I. Cogan, JW. Forster, B.J. Hayes, and H.D. Daetwyler. 2016. Improving genetic gain with genomic selection in autotetraploid potato. Plant Genome 9.

St. Clair, D.A. 2010. Quantitative disease resistance and quantitative resistance loci in breeding. Annual Review of Phytopathology 48: 247-268. https://doi.org/10.1146/annurev-phyto080508-081904.

Stewart, H. E., J. E. Bradshaw, and B. Pande. 2003. The effect of the presence of R-Genes for resistance to late blight (Phytophthora infestans) of potato (Solanum tuberosum) on the underlying level of field resistance. Plant Pathology 52: 193-198. https://doi.org/10.1046/j.1365-3059.2003.00811.x.

Vleeshouwers, V.G.A.A., W. van Dooijeweert, L.C.P. Keizer, L. Sijpkes, F. Govers, and L.T. Colon. 1999. A laboratory assay for Phytophthora infestans resistance in various Solanum species reflects the field situation. European Journal of Plant Pathology 105: 241-250. https://doi.org/10.1023/A:1008710700363.

Voorrips, R.E., G. Gort, and B. Vosman. 2011. Genotype calling in tetraploid species from biallelic marker data using mixture models. BMC Bioinformatics 12: 172. https://doi.org/10.1186/1471-2105-12-172

Vossen, J.H., G. van Arkel, M. Bergervoet, K.R. Jo, E. Jacobsen, and R.G.F. Visser. 2016. The Solanum demissum $R 8$ late blight resistance gene is an $S w-5$ homologue that has been deployed worldwide in late blight resistant varieties. Theoretical and Applied Genetics 129: 1785-1796. https://doi.org/10.1007/s00122-016-2740-0.

Wastie, R.L. 1991. Breeding for resistance. In Phytophthora infestans: the cause of late blight of potato Vol. 7, eds. D.S. Ingram and P.H. Williams. San Diego: Academic Press.

Zych, K., G. Gort, C.A. Maliepaard, R.C. Jansen, and R.E. Voorrips. 2019. FitTetra 2.0 improved genotype calling for tetraploids with multiple population and parental data support. BMC Bionformatics 20: 148. 
bioRxiv preprint doi: https://doi.org/10.1101/2020.09.27.315812; this version posted September 27, 2020. The copyright holder for this preprint (which was not certified by peer review) is the author/funder, who has granted bioRxiv a license to display the preprint in perpetuity. It is made available under aCC-BY-ND 4.0 International license.

Table 1. KASP markers for the R2/Rpi-abpt/Rpi-blb3 locus.

\begin{tabular}{|l|l|l|}
\hline Marker & Rpi-abpt_2223 & R2 (Meade et al. 2020) \\
\hline R/S Alleles & C/T & CGAAA/TGATT \\
\hline Primer R Allele & ACTCAGAACCATCATTGTGATGGAG & AATTCAGCAAATGTAATTTATACTAATTGTTAT \\
\hline Primer S Allele & AAACTCAGAACCATCATTGTGATGGAA & AATTCAGCAAATGTAATTTATACTAATTGTTAA \\
\hline Common Primer & ATAGAGGAACTGCCTCATCTGTTTTCAAA & CTTGCTTGCAACTATACGTAATTGACACTT \\
\hline
\end{tabular}


bioRxiv preprint doi: https://doi.org/10.1101/2020.09.27.315812; this version posted September 27, 2020. The copyright holder for this preprint (which was not certified by peer review) is the author/funder, who has granted bioRxiv a license to display the preprint in perpetuity. It is made available under aCC-BY-ND 4.0 International license.

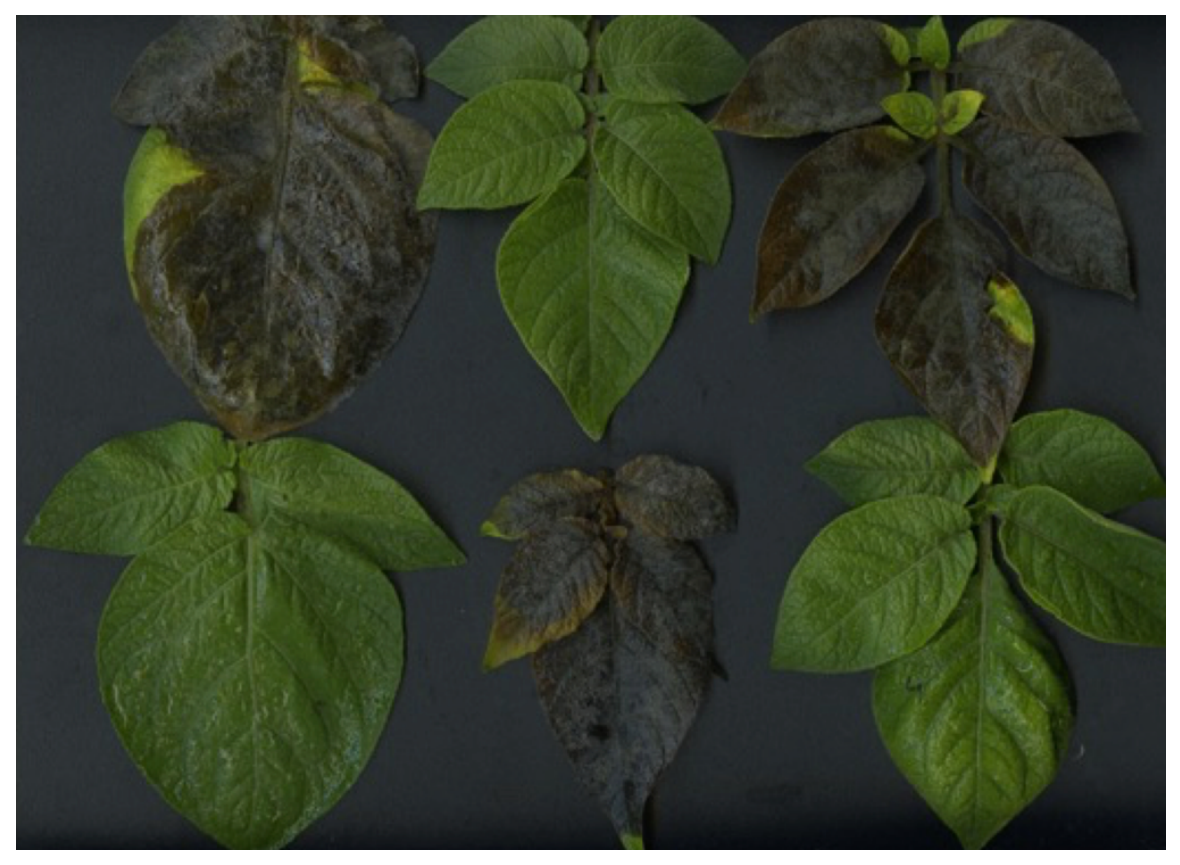

Figure 1. Detached leaf assay for the W16215 (A0012-5 x Payette Russet) mapping population. Photograph illustrates the appearance of resistant vs. susceptible progeny 7 days after infection with a Wisconsin isolate of the $P$. infestans genotype US-23. 


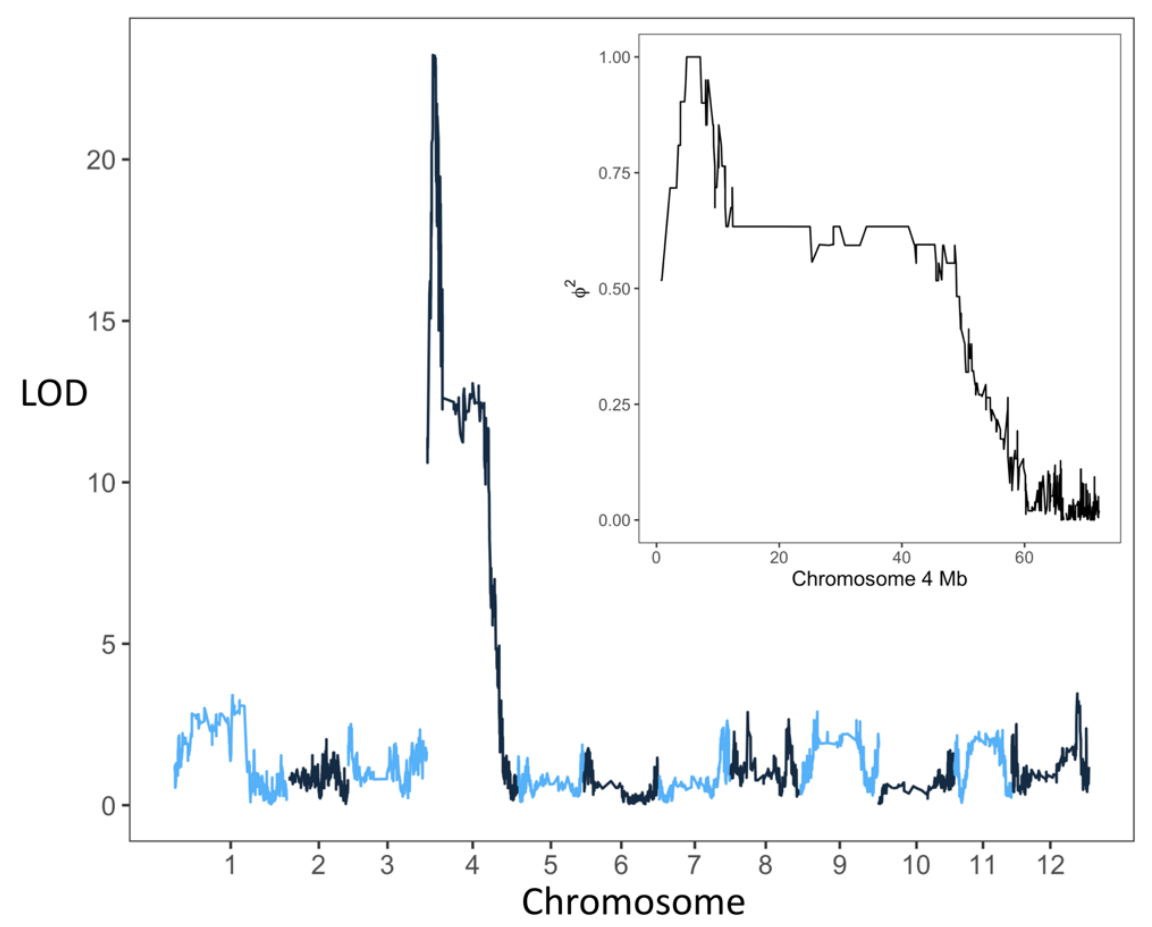

Figure 2. LOD profile based on Bayesian probit regression of the binary resistance trait against parental haplotype probabilities. The peak on chromosome 4 is due to a single haplotype in Payette Russet. Inset: Phi-squared correlation showing the perfect correlation $(=1)$ on the short arm of chromosome 4 . 

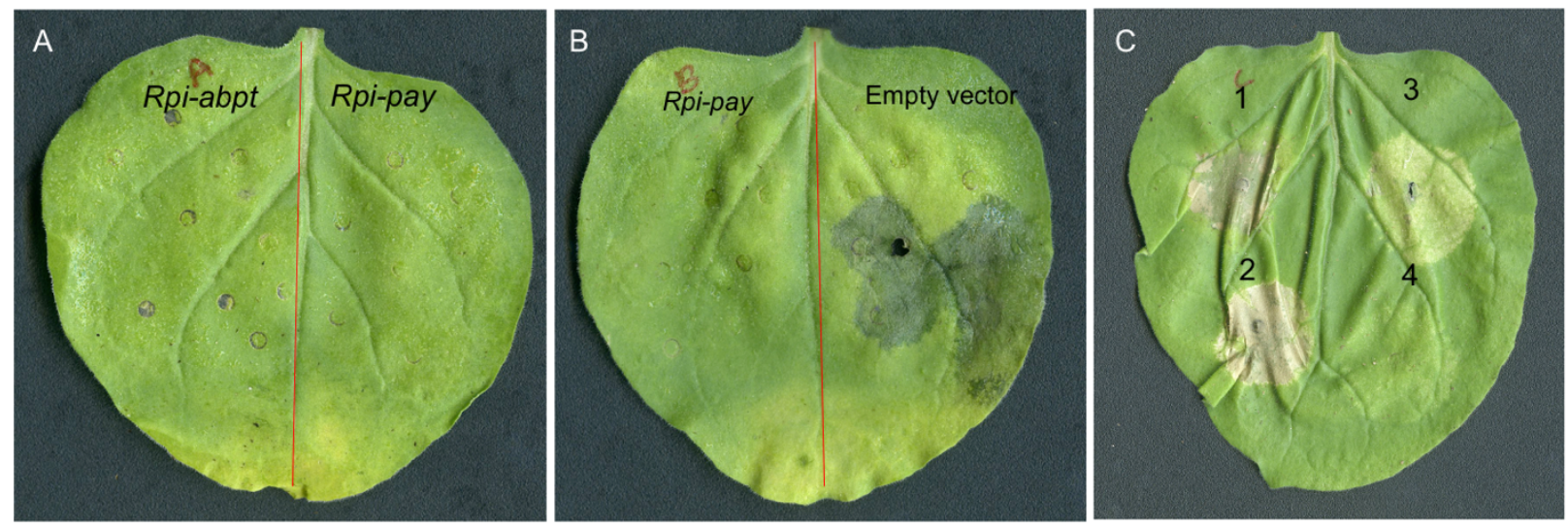

Figure 3. Genetic complementation and effector recognition assay in $N$. benthamiana leaves. (A \& B) Transient expression of Rpi genes followed by inoculation with $P$. infestans genotype US23. Rpi-abpt and empty vector were used as a positive and negative control, respectively.

Photographs were taken 6 days after inoculation. (C) Agrobacterium mediated co-expression of the Avr 2 effector and Rpi genes. Infiltration points correspond to (1) the cell death-inducing elicitin INF 1; (2) Payette R gene + Avr2; (3) Rpi-abpt + Avr2; and (4) Payette R gene alone. Photographs were taken 6 days after co-infiltration. 
bioRxiv preprint doi: https://doi.org/10.1101/2020.09.27.315812; this version posted September 27, 2020. The copyright holder for this preprint (which was not certified by peer review) is the author/funder, who has granted bioRxiv a license to display the preprint in perpetuity. It is made available under aCC-BY-ND 4.0 International license.

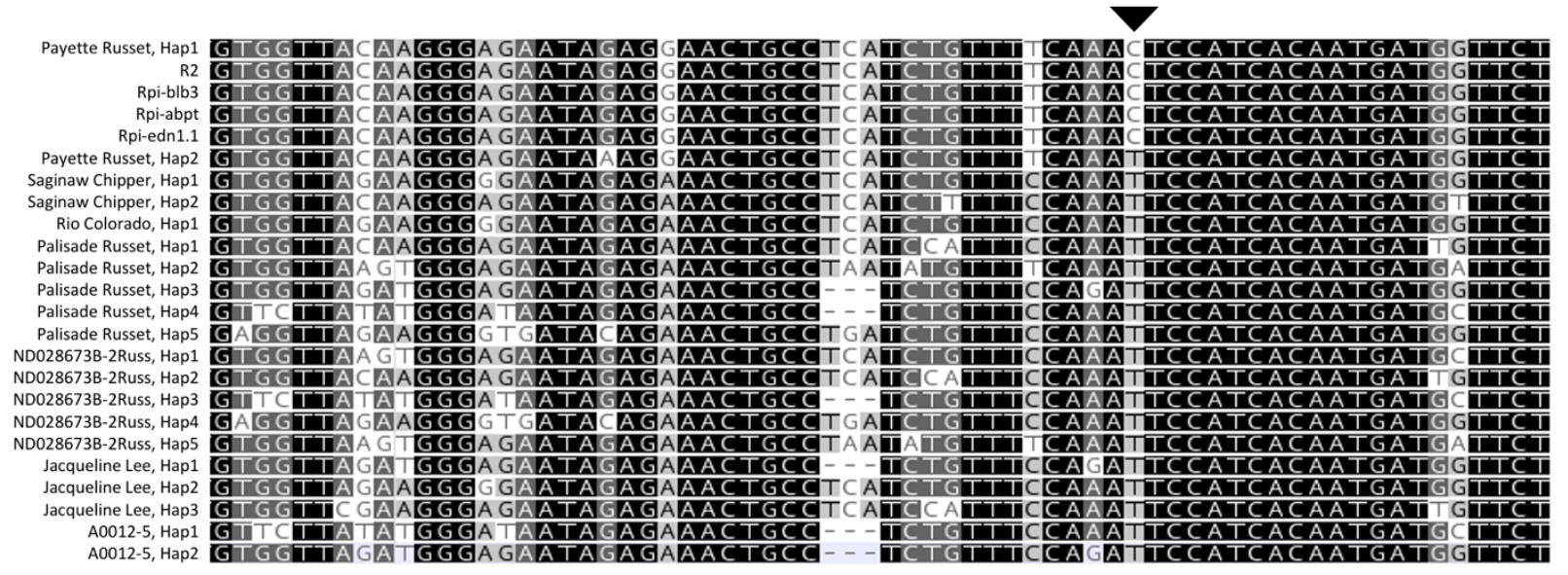

Figure 4. Resistant (rows 1-5) and susceptible (rows 6-24) haplotypes aligned to the Rpi-abpt ${ }^{\mathrm{T} 87}$ haplotype discovered in Payette Russet ("Hap1"). Inverted triangle indicates the C/T SNP used for KASP marker development. 
Supplemental Information

Characterization of a late blight resistance gene homologous to $R 2$ in potato variety Payette Russet

Karki et al. 2020

Table S1. Primer sequences used to amplify $R 2$ homologs.

\begin{tabular}{|l|l|l|}
\hline Primer & Sequence & Reference \\
\hline Forward & GGCTTAAUATGGCTGATGCCTTTCTATCATT & Lokossou et al. (2009) \\
\hline Reverse & GGTTTAAUTCACAACATATAATTCCGCTTCAACA & This study \\
\hline
\end{tabular}

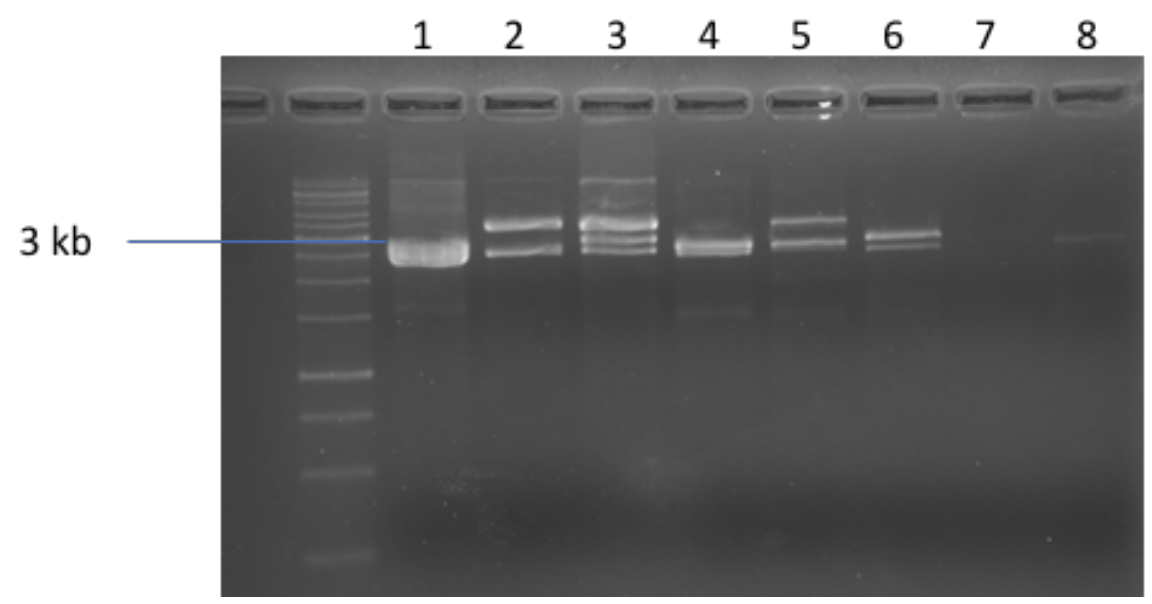

1. Payette

2. A0012-5

3. Palisade

4. Saginaw Chipper

5. Jacqueline Lee

6. ND028673B-2Russ

7. Red Prairie

8. Rio Colorado

Fig S1. Gel electrophoresis of PCR products using the primers in Table S1. 